This is the peer-reviewed version of the article:

Obradović, N., Pavlović, Vera, Kachlik, M., Maca, K., Olćan, D., Đorđević, A., Tshantshapanyan, A., Vlahović, B., Pavlović, Vladimir, 2018. Processing and properties of dense cordierite ceramics obtained through solid-state reaction and pressure-less sintering. Advances in Applied Ceramics.

https://doi.org/10.1080/17436753.2018.1548150

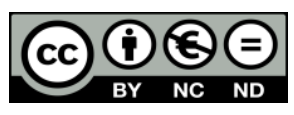

This work is licensed under the Attribution-NonCommercial-NoDerivatives 4.0 International (CC BY-NC-ND 4.0) 


\title{
Processing and properties of dense cordierite ceramics obtained through solid-state reaction and pressure-less sintering
}

\author{
Nina Obradović1, Vera Pavlović , Martin Kachlik ${ }^{3}$, Karel Maca M,4, $^{3,}$ \\ Dragan Olćan $^{5}$, Antonije Đorđevićc, ${ }^{5,6}$ Ani Tshantshapanyan ${ }^{7}$, \\ Branislav Vlahović7, Vladimir Pavlović ${ }^{1}$
}

\author{
${ }^{1}$ Institute of Technical Sciences of SASA, Knez Mihailova 35/IV, 11000 Belgrade, Serbia \\ ${ }^{2}$ Faculty of Mechanical Engineering, Kraljice Marije 16, 11120 Belgrade, Serbia \\ ${ }^{3}$ CEITEC BUT, Brno University of Technology, 61200 Brno, Czech Republic \\ ${ }^{4}$ Faculty of Mechanical Engineering, Brno University of Technology, 61669 Brno, Czech \\ Republic \\ ${ }^{5}$ School of Electrical Engineering, University of Belgrade, Bulevar kralja Aleksandra 73, 11000 \\ Belgrade, Serbia \\ ${ }^{6}$ Serbian Academy of Sciences and Arts, Knez Mihailova 35, 11000 Belgrade, Serbia \\ ${ }^{7}$ North Carolina Central University, Department of Mathematics and Physics, Durham, \\ United States
}

\begin{abstract}
Sintering of pure cordierite $2 \mathrm{MgO}: 2 \mathrm{Al}_{2} \mathrm{O}_{3}: 5 \mathrm{SiO}_{2}$, and cordierite with addition of 5 mass $\% \mathrm{TeO}_{2}$ was studied. Green bodies were prepared from powder mixtures mechanically activated in a high energy planetary mill, shaped by uniaxial (20 MPa) and cold isostatic pressing (1000 MPa). The pressure-less sintering of these specimens was performed at $1350^{\circ} \mathrm{C}$ for $1 \mathrm{~h}$. High relative density over $95 \%$ of theoretical value was obtained through solid-state reaction and pressure-less sintering of powder activated for 40 minutes, and for the first time reported in the literature. Phase composition and microstructures of sintered samples were determined by XRD and SEM, coupled with EDS mapping. The real part of the complex relative permittivity of the samples was measured at $200 \mathrm{MHz}$. The loss tangent of all samples was below the resolution of the measurement setup. A strong correlation between the relative permittivity and the density agrees with previously published data.
\end{abstract}


Keywords: Mechanical activation, Sintering, Electrical properties, Cordierite, $\mathrm{TeO}_{2}$.

*Corresponding author: maca@fme.vutbr.cz (Prof. Dr. Karel Maca)

\section{Introduction}

Cordierite $\left(2 \mathrm{MgO} \cdot 2 \mathrm{Al}_{2} \mathrm{O}_{3} \cdot 5 \mathrm{SiO}_{2}\right)$ based ceramics are widely used in various fields, e.g. as substrates for micro-electronic packaging industry and cookware, heat exchangers, glazes for floor tiles, etc. Owing to relative low dielectric constant $(\sim 5)$ and very low CTE $\left(<2 \cdot 10^{-6}{ }^{\circ} \mathrm{C}^{-1}\right)$, these ceramics are also well known by their good thermo-mechanical, chemical, and dielectric properties [1-3]. Due to their excellent resistance to the thermal shock they can be applicable as materials that are exposed to sudden temperature changes [4-8] and also as semi-conducting bearers $[9,10]$.

Cordierite is difficult to sinter due to its very narrow sintering temperature range (1300$1400{ }^{\circ} \mathrm{C}$ ) [11]. Because a low temperature process is desirable, it is beneficiary to found functional aids which can allow easier process of sintering at lower temperature. The melting temperature of these additives should be lower than that of the precursors. In addition, the cationic radius should be larger than the radius of the metals in MAS to avoid the substitution into cordierite sites. Different components have been used as sintering aids, such as $\mathrm{Cr}_{2} \mathrm{O}_{3}, \mathrm{ZrO}_{2}, \mathrm{~K}_{2} \mathrm{O}, \mathrm{TiO}_{2}, \mathrm{Bi}_{2} \mathrm{O}_{3}$, $\mathrm{MoO}_{3}$, etc. $[12,13]$. Also, $\mathrm{TeO}_{2}$ fulfils the theoretical criteria of large atomic radius (142 pm) and low melting temperature $733{ }^{\circ} \mathrm{C}$ ), therefore the experimental study of its influence on sintering and electrical properties of cordierite ceramics is needed and desirable.

Our previous study [14] shows that the mechanical activation of starting components (kaolin, quartz, magnesium oxide) has a significant impact on the decrease of the sintering temperature. It has been demonstrated that, compared to non-activated components, mechanically activated ones increase their energy due to induced crystal defects. During a mechanochemical treatment, several processes occur, such as attrition of the starting material, crystal lattice destruction, chemical reactions, the formation of various defects, etc. All of the mentioned processes increase the chance for reactions to occur at temperatures lower than usual [15]. Furthermore, mechanical activation could affect the final electrical characteristics; hence, it is very important to take into account and understand the changes that are introduced into the system during milling. 
According to our best knowledge, there have been no attempts to investigate the effect of mechanical activation along with $\mathrm{TeO}_{2}$ addition, followed by pressure-less sintering for cordieritebased ceramics and investigation of all those parameters on densification, and physical-chemical properties. The main objective of this work is to investigate the effects of the mechanical activation, $\mathrm{TeO}_{2}$ addition, and pressure-less sintering of cordierite-based material on its phase composition, microstructure, and electrical properties.

\section{Materials and methods}

Mixtures of $\mathrm{MgO}, \mathrm{Al}_{2} \mathrm{O}_{3}, \mathrm{SiO}_{2}$, and $\mathrm{TeO}_{2}$ starting powders (all $99 \%$ Sigma-Aldrich, p.a.) were used in these experiments. The mixtures of $\mathrm{MgO}+\mathrm{Al}_{2} \mathrm{O}_{3}+\mathrm{SiO}_{2}$ in the 2:2:5 molar ratio, with and without the addition of 5 mass $\% \mathrm{TeO}_{2}$, were mechanically activated by grinding in a highenergy planetary ball mill (Fritsch Pulverisette 5). $\mathrm{ZrO}_{2}$ vessels and balls were used with the powder-to-balls mass ratio of 1:40. The milling process was performed in air for 10 and 40 minutes. The samples were denoted as MAS-0, MAS-10, MAS-40, MAS-0-Te, MAS-10-Te, and MAS-40-Te (according to activation time, and $\mathrm{TeO}_{2}$ addition).

The green bodies in the shape of cylinders (diameter $14 \mathrm{~mm}$, height $4 \mathrm{~mm}$ ) were prepared by uniaxial pressing at $20 \mathrm{MPa}$, followed by cold isostatic pressing at $1000 \mathrm{MPa}$. Sintering was performed at $1350{ }^{\circ} \mathrm{C}$, with a heating rate of $10^{\circ} \mathrm{C} \min ^{-1}$ and dwell time of $1 \mathrm{~h}$. The apparent densities and the ratio of open porosity of sintered samples were determined by Archimedes method in distilled water (EN 623-2).

The X-ray powder diffraction patterns were obtained using a Philips PW-1050 diffractometer with $\lambda \mathrm{Cu}-\mathrm{K}_{\alpha}$ radiation and a step/time scan mode of $0.05^{\circ} \mathrm{s}^{-1}$. The measurements were performed at the room temperature in air atmosphere.

The morphology of the sintered samples was characterized by the scanning electron microscopy (JEOL JSM-6390 LV). The samples were crushed and covered with gold in order to perform these measurements.

Raman spectra of all powders, recorded in the $200-1100 \mathrm{~cm}^{-1}$ range, were collected with a LabRAM HR Evolution system which employed Cobolt Blues ${ }^{\mathrm{TM}} 473 \mathrm{~nm}$ solid state laser with power of $1 \mathrm{~mW}$ at the sample surface. All the measurements were realized using a spectrometer 
equipped with a grating having 1800 lines $\mathrm{mm}^{-1}$, a $100 \mathrm{x}$ microscope objectives and acquisition of $20 \mathrm{~s} / 10$ cycles.

The measurements of the relative permittivity of the sintered samples, metallized on the top and bottom with silver, were performed using an Agilent E5061A network analyzer. The samples were placed in a coaxial chamber [16]. The reflection coefficient of the chamber was measured by the analyzer and the relative complex permittivity of the samples was extracted using electromagnetic models.

\section{Results and discussion}

The phase compositions of the non-activated and activated samples after the sintering process without addition of $\mathrm{TeO}_{2}$ are presented in Figure 1. The XRD pattern of the initial nonactivated sintered sample indicates that several phases $-\mathrm{Mg}_{2} \mathrm{Al}_{4} \mathrm{Si}_{5} \mathrm{O}_{18}, \mathrm{SiO}_{2}, \mathrm{Mg}_{2} \mathrm{SiO}_{4}, \alpha-\mathrm{Al}_{2} \mathrm{O}_{3}$, and $\mathrm{MgSiO}_{3}$ - are present within MAS-0 sintered mixture. The formation of cordierite began even during the sintering of the starting mixture, although significant amounts of the starting phase $\mathrm{SiO}_{2}$ and intermediate compound $\mathrm{MgSiO}_{3}$ are present. The phase $\mathrm{MgSiO}_{3}$ is no longer present in the sintered samples MAS-10 and MAS-40, which means that the intermediate compound reacted further and produced increased amounts of cordierite (from $63.6 \%$ for MAS-10 to $69.8 \%$ for MAS-40) and decreased amounts of $\mathrm{Mg}_{2} \mathrm{SiO}_{4}$ and $\mathrm{Al}_{2} \mathrm{O}_{3}$ phases (from $17.1 \%$ for MAS-10 to $13 \%$ for MAS-40, and $5.6 \%$ for MAS-10 to $2.4 \%$ for MAS-40, respectively). The diffraction patterns of the activated and sintered samples, besides well crystallized sharp peaks of cordierite, show small amount of $\mathrm{ZrSiO}_{4}$ (approx. $2.5 \%$ ) due to the high-energy ball milling in $\mathrm{ZrO}_{2}$ jar with balls made of the same material.

Figure 1. XRD patterns of sintered MAS-0, MAS-10, and MAS-40 samples.

The phase compositions of the non-activated and activated samples with addition of $\mathrm{TeO}_{2}$ after the sintering process are presented in Figure 2. All phases that are present in the sintered mixture MAS-0, are detected in the mixture MAS-0-Te as well, with the presence of some $\mathrm{TeO}_{2}$, 
namely in the sample MAS-40-Te. Also, the presence of $\mathrm{ZrSiO}_{4}$ phase is identified in the activated and sintered samples, along with the absence of the intermediate compound $\mathrm{MgSiO}_{3}$, present only in the non-activated sintered mixture. The only difference with respect to the sintered mixtures without $\mathrm{TeO}_{2}$ is the absence of $\mathrm{SiO}_{2}$ phase in the MAS-40-Te sample. The identification of the obtained reflections was carried out using JCPDS cards (075-1439 for cordierite, 082-1403 for $\mathrm{SiO}_{2}, 089-1625$ for $\mathrm{Mg}_{2} \mathrm{SiO}_{4}, 081-2267$ for $\alpha-\mathrm{Al}_{2} \mathrm{O}_{3}$, 011-0273 for $\mathrm{MgSiO}_{3}, 083-1375$ for $\mathrm{ZrSiO}_{4}$, and $052-1005$ for $\gamma-\mathrm{TeO}_{2}$ ).

Figure 2. XRD patterns of sintered MAS-0-Te, MAS-10-Te, and MAS-40-Te samples.

Values of the apparent densities and ratio of open porosity of the sintered samples, determined by Archimedes method, are given in Table 1. The lowest density is obtained for the non-activated sample with $\mathrm{TeO}_{2}$ addition $\left(2.21 \mathrm{~g} \cdot \mathrm{cm}^{-3}\right)$, while the highest value is obtained for the sample activated for 40 minutes and sintered without $\mathrm{TeO}_{2}\left(2.60 \mathrm{~g} \cdot \mathrm{cm}^{-3}\right)$, which makes it very dense. According to literature data, there are many papers dealing with dense cordierite ceramics. A recent paper by D. Redaoui et al. reports samples with apparent density $2.50 \mathrm{~g} \cdot \mathrm{cm}^{-3} \mathrm{obtained}$ from naturally occurring clay minerals, milled for 20 hours in wet media, calcined for $24 \mathrm{~h}$, and then sintered at $1250{ }^{\circ} \mathrm{C}$ [17], and Neto\&Moreno reported even the density $2.58 \mathrm{~g} \cdot \mathrm{cm}^{-3}$ for cordierite ceramics obtained for samples produced from mechanically activated kaolin/talc/alumina powders and sintered at $1350{ }^{\circ} \mathrm{C}$ for $1 \mathrm{~h} \mathrm{[18].} \mathrm{In} \mathrm{this} \mathrm{regard} \mathrm{the} \mathrm{density} \mathrm{of} \mathrm{the}$ ceramics obtained in this work is according to our best knowledge the highest density reported for cordierite based ceramics obtained after mechanical activation and pressure-less sintering. Moreover, these samples did not contain open pores (see Table 1) so we have reached the relative density above $95 \%$ of theoretical density of this composition [19]. The densities of the sintered samples with $\mathrm{TeO}_{2}$ are slightly lower with respect to the samples without it, anyway also the doped sample activated for 40 minutes reached high apparent density $\left(2.56 \mathrm{~g} \cdot \mathrm{cm}^{-3}\right)$ together with minimal content of open pores. Due to its low melting point $\left(733^{\circ} \mathrm{C}\right), \mathrm{TeO}_{2}$ should serve as a transient liquid-phase sintering aid [20] in the initial and intermediate sintering stage and due to its low boiling point $\left(1250{ }^{\circ} \mathrm{C}\right)$ evaporate from the sample before reaching the final sintering stage. For a better evaluation of the proposed transient liquid-phase sintering mechanism the use of different $\mathrm{TeO}_{2}$ concentration would be necessary. 
Table 1. Apparent density and relative open porosity of sintered samples.

A scanning electron micrograph, along with EDS mapping of the sintered sample MAS-0 is presented in Figure 3. During the sintering of the non-activated powder, formation of irregularly shaped pores is noticed, although there are some parts where spherical pores are visible as well. Uneven phase distribution is present, along with sintered particles that were not part of agglomerates in the initial powder.

Figure 3. a) SEM, b) EDS mapping of MAS-0 sintered sample.

Prolonged activation for 40 minutes, followed by sintering, led to a completely sintered and dense sample, with a homogeneous structure, presented in Figure 4. The mapping image indicates an even and homogeneous phase distribution. No spherical (closed) pores are detected, indicating very high relative density of the sample.

Figure 4. a) SEM, b) EDS mapping of MAS-40 sintered sample.

Contrary to the MAS-0 sample, sintering of MAS-0-Te sample showed melting and formation of a liquid phase during the sintering regime. The micrograph presented in Figure 5 indicates parts of the microstructure where some sintered powder particles are coated with the liquid phase, which enables process of mass transport. The mapping shows that Te is distributed along the grains of the sintered material, either as the residual $\mathrm{TeO}_{2}$ or dissolved in the matrix.

Figure 5. a) SEM, b) EDS mapping of MAS-0-Te sintered sample.

Finally, continual parts that are well sintered are visible within the sintered sample activated for 40 minutes with addition of $\mathrm{TeO}_{2}$, as seen in Figure 6. Besides, a porous structure is still present, with contact necks that are strengthened during sintering. This microstructure indicates the final sintering stage due to the presence of the closed porosity (see Table 1). The microstructure of the initial powder activated 40 minutes with $\mathrm{TeO}_{2}$, was non-uniform and 
sintering of that kind of a structure leads to formation of non-uniformly shaped pores. $\mathrm{TeO}_{2}$ phase remains on the grain boundaries, while the part of the liquid phase remains within the sintered sample.

Figure 6. a) SEM, b) EDS mapping of MAS-40-Te sintered sample.

Figure 7 presents Raman spectra of cordierite-based ceramics in the range of wavenumbers of $200-1100 \mathrm{~cm}^{-1}$. Beside cordierite peaks, in the Raman spectra of the non-activated sintered samples peaks of $\mathrm{SiO}_{2}$ (cristobalite), $\mathrm{Mg}_{2} \mathrm{SiO}_{4}$ (ringwoodite), $\mathrm{MgSiO}_{3}$ (enstatite), and $\mathrm{Al}_{2} \mathrm{O}_{3}$ are also pronounced [21-24], which is in a good accordance with the results obtained using XRD measurements (see Figures 1 and 2). From the Raman spectra, it can be assumed that there is also a possible existence of $\mathrm{MgAl}_{2} \mathrm{O}_{4}$ in the samples, but the fact that major lines of this spinel overlap with lines of some other present phases, especially with the most intensive lines of the $\mathrm{SiO}_{2}$ and $\mathrm{Al}_{2} \mathrm{O}_{3}$, impedes precise assessment [24]. The presence of $\mathrm{MgAl}_{2} \mathrm{O}_{4}$ phase wasn't explicitly detected using XRD measurement, but the overlapping of its diffractions with $\mathrm{Mg}_{2} \mathrm{SiO}_{4}$ diffractions could influence the XRD estimations to some extent, as well. The Raman spectra pointed out that the share of mentioned non-cordierite phase's decreases with the activation time, which is followed by the increase in amount of cordierite. The influence of the mechanical activation is most visible in decrease of the reflections at $\sim 230 \mathrm{~cm}^{-1}$ and $\sim 416 \mathrm{~cm}^{-1}$, relative to the strongest cordierite peak. The change is prominent even for the sample activated for 10 minutes, and is more pronounced with prolonged activation time. The position of the peak assigned to the superposition of the strongest lines of $\mathrm{SiO}_{2}, \mathrm{Al}_{2} \mathrm{O}_{3}$ and $\mathrm{MgAl}_{2} \mathrm{O}_{4}$ phases is shifted towards lower frequencies, from $416 \mathrm{~cm}^{-1}$ to $407 \mathrm{~cm}^{-1}$, with the increase of the activation time. The strongest cordierite peak indicates the existence of the orthorhombic modification of $\mathrm{Mg}$-cordierite phase, present in spectra of the non-activated sintered samples. The existence of that modification is manifested in clearly visible asymmetry of the strongest peak and its partial splitting, where the line at $\sim 564 \mathrm{~cm}^{-1}$ occurs along with the shoulder on the side of higher frequencies $\left(575-585 \mathrm{~cm}^{-}\right.$ $\left.{ }^{1}\right)$ [25]. That trend is more noticeable in the samples with $\mathrm{TeO}_{2}$ addition. The appearance of the asymmetry and splitting of the cordierite peak is related to Al-Si ordering within the cordierite structure (with bending vibration of $\mathrm{T}_{2} 6, \mathrm{~T}_{2} 1$, and $\mathrm{T}_{2} 3$ units), as well as with simultaneous stretching vibrations of the $M$ and $T_{2} 6$ sites in the structure [26]. The asymmetry is markedly 
reduced for prolonged activation time and cordierite peaks can be assigned predominantly to the hexagonal modification in these samples.

Figure 7. Raman spectra of sintered samples MAS-0, MAS-10, MAS-40, MAS-0-Te, MAS-10-Te, and MAS-40-Te (C - cordierite, E - enstatite $\mathrm{MgSiO}_{3}, \mathrm{RW}$ - ringwoodite $\mathrm{Mg}_{2} \mathrm{SiO}_{4}, \mathrm{~A}$ - alpha- $\mathrm{Al}_{2} \mathrm{O}_{3}, \mathrm{SiO}_{2}$ - cristobalite, $\mathrm{S}$ - spinel $\mathrm{MgAl}_{2} \mathrm{O}_{4}$, and $\mathrm{Z}-\mathrm{ZrSiO}_{4}$ ).

Although the origin of peaks at $\sim 703 \mathrm{~cm}^{-1}$ and $\sim 901 \mathrm{~cm}^{-1}$ in non-activated sintered samples is not known precisely, it is assumed that the first one could be assigned to the existence of $\delta(\mathrm{O}-\mathrm{Al}-\mathrm{O})$ vibrations, while the other one corresponds to $\mathrm{Si}-\mathrm{O}-\mathrm{Si}(\mathrm{Al})$ vibrations [27]. Two most intensive lines of $\mathrm{TeO}_{2}$ phase contribute to the peaks at $\sim 226 \mathrm{~cm}^{-1}$ and $660 \mathrm{~cm}^{-1}$, in samples with $\mathrm{TeO}_{2}$ addition. With the extended activation time, the presence of $\mathrm{ZrSiO}_{4}$ peak at $\sim 354 \mathrm{~cm}^{-1}$ is noticed, so we concluded that this phase is also present within the peaks at $438 \mathrm{~cm}^{-1}$ and $1006 \mathrm{~cm}^{-1}$, although those peaks dominantly originate from the cordierite phase.

The results for the real part of the complex relative permittivity (dielectric constant) of the samples, measured at $200 \mathrm{MHz}$, are shown in Table 2. The loss tangent for all samples was very small, below the resolution of the measurement setup $(<0.005)$.

Table 2. Real part of complex relative permittivity of sintered samples.

There is a strong correlation between the relative permittivity and the density (resp. residual porosity), which agrees with our previous results [28, 29], when the relative permittivity follows the trend of the density changes (see Table 1). Furthermore, if we compare the changes in densities with the activation time, an increase of the density with the prolonged milling time is noticed, owing to a lower porosity and a more compact structure which is observed as changes in the microstructures (see Figures 3-6). This suggests that the higher density and the homogeneity of the morphology are dominantly responsible for the higher permittivity of the samples. The better packaging the starting powder, of activated and hence more reactive particles, facilitated sintering. Strengthening of grain boundaries occurred, and consequently the relative density increased [29]. According to available physical models, porous materials exhibit similar dielectric characteristics 
as composites, where the porosity (air) is considered to be one of their components [30]. Figure 8 shows results from three sets of measurements of cordierite-based ceramics. The data are clustered around the fitting curve for mixtures (logarithmic linear approximation of the Lichtenecker's model) [31], given by $\frac{\ln \varepsilon_{\mathrm{r}}^{\prime}}{\ln \varepsilon_{\mathrm{r} \max }^{\prime}}=\frac{\rho}{\rho_{\max }}$, where the relative permittivity of one component (air) is 1, and $\varepsilon_{\mathrm{r} \text { max }}^{\prime}=6$ is the relative permittivity of the second component at the highest density (when no open porosity is present) $\rho_{\max }=2.6 \mathrm{~g} \cdot \mathrm{cm}^{-3}$. Note that $\varepsilon_{\mathrm{r} \max }^{\prime}$ and $\rho_{\max }$ are our estimates, because reliable data were not available in the literature. This model was selected because it gives a better prediction of permittivity of multi-phase materials than other models (e.g., Maxwell-Garnett) [32].

Figure 8. Measured relative permittivity as a function of density, along with logarithmic fitting curve. The first set of samples is from [28] and the second set is from [29].

\section{Conclusions}

In the present study, cordierite-based ceramics materials were prepared using mechanical activation followed by pressure-less sintering. The phase composition, microstructure, and electric properties of the bulk materials were characterized systematically. The most important conclusions are:

(1) Pressure-less sintering of investigated powders leads to cordierite formation. The formation of cordierite began even during the sintering of the non-activated starting mixture, with $\mathrm{SiO}_{2}$ and $\mathrm{MgSiO}_{3}$ phases. The phase $\mathrm{MgSiO}_{3}$ is no longer present in the sintered samples MAS-10 and MAS-40, meaning that the intermediate compound reacted further and produced increased amounts of cordierite. MAS-10 and MAS-40 sintered samples, besides well crystallized sharp peaks of cordierite, show small amount of $\mathrm{ZrSiO}_{4}$ due to the contamination during high-energy ball milling. The phase composition of sintered samples with $\mathrm{TeO}_{2}$ remains, but the presence of $\mathrm{TeO}_{2}$ is noticed. Raman analysis confirmed that the share of non-cordierite phase's decreases with the activation time, which is followed by the increase in cordierite amount, where 


\section{Acknowledgement}

The authors acknowledge financial support from Ministry of Education, Science and Technological development of Serbia, Project No. OI 172057. The part of experiments was conducted within the following projects: NSF: HRD-1345219 and DMR-1523617; NASA: NNX09AV07A; GACR: 17-05620S; MEYS of CR: CEITEC 2020 (LQ1601). The authors are grateful to Dr. Miodrag Mitrić for XRD measurement, Dr. Nataša Đorđević and Dr. Darko Kosanović for mechanical activation.

\section{References}


[1] A. I. Kingon, R. F. Davis, Engineer Materials Handbook, Vol. 2. "Ceramics” edited by S. J. Schneider, Jr., ASM International Metals Park, OH, (1991) 758.

[2] N. Obradovic, N. Djordjevic, S. Filipovic, N. Nikolic, D. Kosanovic, M. Mitric, S. Markovic, V. Pavlovic, Powder Technology 218 (2012) 157.

[3] N. Obradović, S. Filipović, N. Đorđević, D. Kosanović, S. Marković, V. Pavlović, D. Olćan, A. Đorđević, M. Kachlik, K. Maca, Effects of mechanical activation and two-step sintering on the structure and electrical properties of cordierite-based ceramics, Ceramics International 42 (2016) 13909.

[4] V. J. Powers, C. H. Drummond, Ceram. Eng. Sci. Proc. 7 (1986) 969.

[5] I. Warsworth, R. Stevens, J. Eur. Ceram. Soc. 9 (1992) 153.

[6] M. Pinero, M. Atik, J. Zarzycki, J. Non-Cryst. Solids 147-148 (1992) 1523.

[7] D. Kervadec, M. Coster, J. L. Chermant, Mater. Res. Bull. 27 (1992) 967.

[8] N. Clausen, G. Petzow, J. Phys. (Paris), 47 (1986) 693.

[9] R. R. Tumala, J. Am. Ceram. Soc. 74 (1991) 895.

[10] S. H. Knickerbocker, A. H.Kumar, L. W. Herron Am. Ceram. Soc. Bull. 72 (1993) 90.

[11] A. Peleš, N. Đorđević, N. Obradović, N. Tadić, V. B. Pavlović, "Influence of prolonged sintering time on density and electrical properties of isothermally sintered cordierite-based ceramics", Science of Sintering, 45 (2013) 157.

[12] K. Kondo, M. Okuyama, Y. Shibata, “Advances in ceramics”, Vol. 19, edited by J. B. Blum and R. Cannon (American Ceramic Society Inc., Ohio, 1986).

[13] N. Đorđević, N. Obradović, D. Kosanović, M. Mitrić, V. P. Pavlović, Sintering of Cordierite in the Presence of $\mathrm{MoO}_{3}$ and Crystallization Analysis, Science of Sintering, 46 (2014) 307.

[14] N. Djordjevic, N. Obradovic, S. Filipovic, J. Zivojinovic, M. Mitric, S. Markovic, Tehnika Novi materijali 21 (2012) 3, 329.

[15] N. Obradović, N. Đorđević, A. Peleš, S. Filipović, M. Mitrić, V. B. Pavlović, The Influence of Compaction Pressure on the Density and Electrical Properties of Cordierite-based Ceramics, Science of Sintering, 47 (2015) 15.

[16] A. Đorđević, J. Dinkić, M. Stevanović, D. Olćan, S. Filipović, N. Obradović, Measurement of Permittivity of Solid and Liquid Dielectrics in Coaxial Chambers, Microwave Review 22:2 (2016) 3 . 
[17] D. Redaoui, F. Sahnoune, M. Heraiz, N. Saheb, Phase formation and crystallization kinetics in cordierite ceramics prepared from kaolinite and magnesia, Ceramics International 44 (2018) 3649 .

[18] J. B. R. Neto, R. Moreno, Effect of mechanical activation on the rheology and casting performance of kaolin/talc/alumina suspensions for manufacturing dense cordierite bodies, Applied Clay Science 38 (2008) 209.

[19] T. Spusta, J. Svoboda, K. Maca, Study of pore closure during pressure-less sintering of advanced oxide ceramics, Acta Materialia 115 (2016) 347.

[20] L. A. Chick et al., Phase Transitions and Transient Liquid-Phase Sintering in CalciumSubstituted Lanthanum Chromite, Journal of American Ceramic Society, 80 [8] (1997) 2109. [21] J. B. Bates, Raman Spectra of $\alpha$ and $\beta$ Cristobalite, the Journal of Chemical Physics 57 (1972) 4042.

[22] A-C. Zhang, W-B. Hsu, C. Floss, X-H. LI, Q-L. LI, Y. Liu, L, A. Taylor, Petrogenesis of lunar meteorite Northwest Africa 2977: Constraints from in situ microprobe results, Meteoritics \& Planetary Science 1-19 (2010) 1.

[23] B. Reynard, J. D. Bass, J. M. Jackson, Journal of the European Ceramic Society 28 (2008) 2459 .

[24] D. Errandonea, $\mathrm{AB}_{2} \mathrm{O}_{4}$ Compounds at High Pressures, Chapter 2 in Pressure-Induced Phase Transitions in AB2X4 Chalogenide Compounds, Manjon; F.J., Tiginyanu, I.; Ursaki V. (Eds.) 2014, XIII, 243p, Hardcover, Springer, ISBN: 978-3-642-40366-8.

[25] U. Haefeker, R. Kaindl, P. Tropper, Semi-quantitative determination of the Fe/Mg ratio in synthetic cordierite using Raman spectroscopy, American Mineralogist 97 (2012) 1662.

[26] R. Kaindl, D. M. Többens, U. Haefeker, Quantum-mechanical calculations of the Raman spectra of Mg- and Fe-cordierite, American Mineralogist 96 (2011) 1568.

[27] V. Šontevska, G. Jovanovski, P. Makreski, A. Raškovska, B. Šoptrajanov, Minerals From Macedonia. XXI. Vibrational Spectroscopy as Identificational Tool for Some Phyllosilicate Minerals, Acta Chimica Slovakia 55 (2008) 757.

[28] Nina N. Obradović, Synthesis of cordierite-based ceramics, Monograph, Academic mind, Belgrade, Serbia, 2016. 
[29] N. Obradović, S. Filipović, N. Đorđević, D. Kosanović, V. Pavlović, D. Olćan, A. Đorđević, M. Kachlik, K. Maca, Microstructural and Electrical Properties of Cordierite-based Ceramics Obtained After Two-step Sintering Technique, Science of Sintering, 48 (2016) 157.

[30] D. J. Bergman, The dielectric constant of a composite material - a problem in classical physics*, Physics Reports (Section C of Physics Letters) 43 (1978) 377.

[31] K. Lichtenecker, Die Dielektrizitatskonstante naturlicher und kunstlicher Mischkorper, K. Phys. Zeitschrift 27 (1926) 115.

[32] T. P. Leao, E. Perfect, J. S. Tyner, Evaluation of Lichtenecker's Mixing Model for Predicting Effective Permittivity of Soils at $50 \mathrm{MHz}$, American Society of Agricultural and Biological Engineers 58 (2015) 83. 
Table 1. Apparent density and relative open porosity of sintered samples

\begin{tabular}{ccc}
\hline Sample & $\begin{array}{c}\text { Apparent density } \\
\left(\mathbf{g} / \mathbf{c m}^{\mathbf{3}}\right)\end{array}$ & $\begin{array}{c}\text { Relative open porosity } \\
(\text { vol. \%) }\end{array}$ \\
\hline MAS-0 & 2.45 & 10.8 \\
MAS-10 & 2.32 & 12.0 \\
MAS-40 & 2.60 & 0.0 \\
\hline MAS-0-Te & 2.21 & 18.5 \\
MAS-10-Te & 2.29 & 13.5 \\
MAS-40-Te & 2.56 & 0.5 \\
\hline
\end{tabular}


Table 2. The real part of complex relative permittivity of sintered samples

\begin{tabular}{cc}
\hline Sample & $\boldsymbol{\varepsilon r}^{\prime}$ \\
\hline MAS-0 & 5.24 \\
MAS-10 & 4.99 \\
MAS-40 & 5.55 \\
\hline MAS-0-Te & 4.96 \\
MAS-10-Te & 4.96 \\
MAS-40-Te & 5.54 \\
\hline
\end{tabular}


Figure Captions

Figure 1. XRD patterns of sintered MAS-0, MAS-10, and MAS-40 samples.

Figure 2. XRD patterns of sintered MAS-0-Te, MAS-10-Te, and MAS-40-Te samples.

Figure 3. a) SEM, b) EDS mapping of MAS-0 sintered sample.

Figure 4. a) SEM, b) EDS mapping of MAS-40 sintered sample.

Figure 5. a) SEM, b) EDS mapping of MAS-0-Te sintered sample.

Figure 6. a) SEM, b) EDS mapping of MAS-40-Te sintered sample.

Figure 7. Raman spectra of sintered samples MAS-0, MAS-10, MAS-40, MAS-0-Te, MAS-10Te, and MAS-40-Te (C - cordierite, $\mathrm{E}$ - enstatite $\mathrm{MgSiO}_{3}, \mathrm{RW}$ - ringwoodite $\mathrm{Mg}_{2} \mathrm{SiO}_{4}, \mathrm{~A}-$ alpha- $\mathrm{Al}_{2} \mathrm{O}_{3}, \mathrm{SiO}_{2}$ - cristobalite, $\mathrm{S}$ - spinel $\mathrm{MgAl}_{2} \mathrm{O}_{4}$, and $\mathrm{Z}-\mathrm{ZrSiO}_{4}$ ).

Figure 8. Measured relative permittivity as a function of density, along with logarithmic fitting curve. The first set of samples is from [28] and the second set is from [29]. 


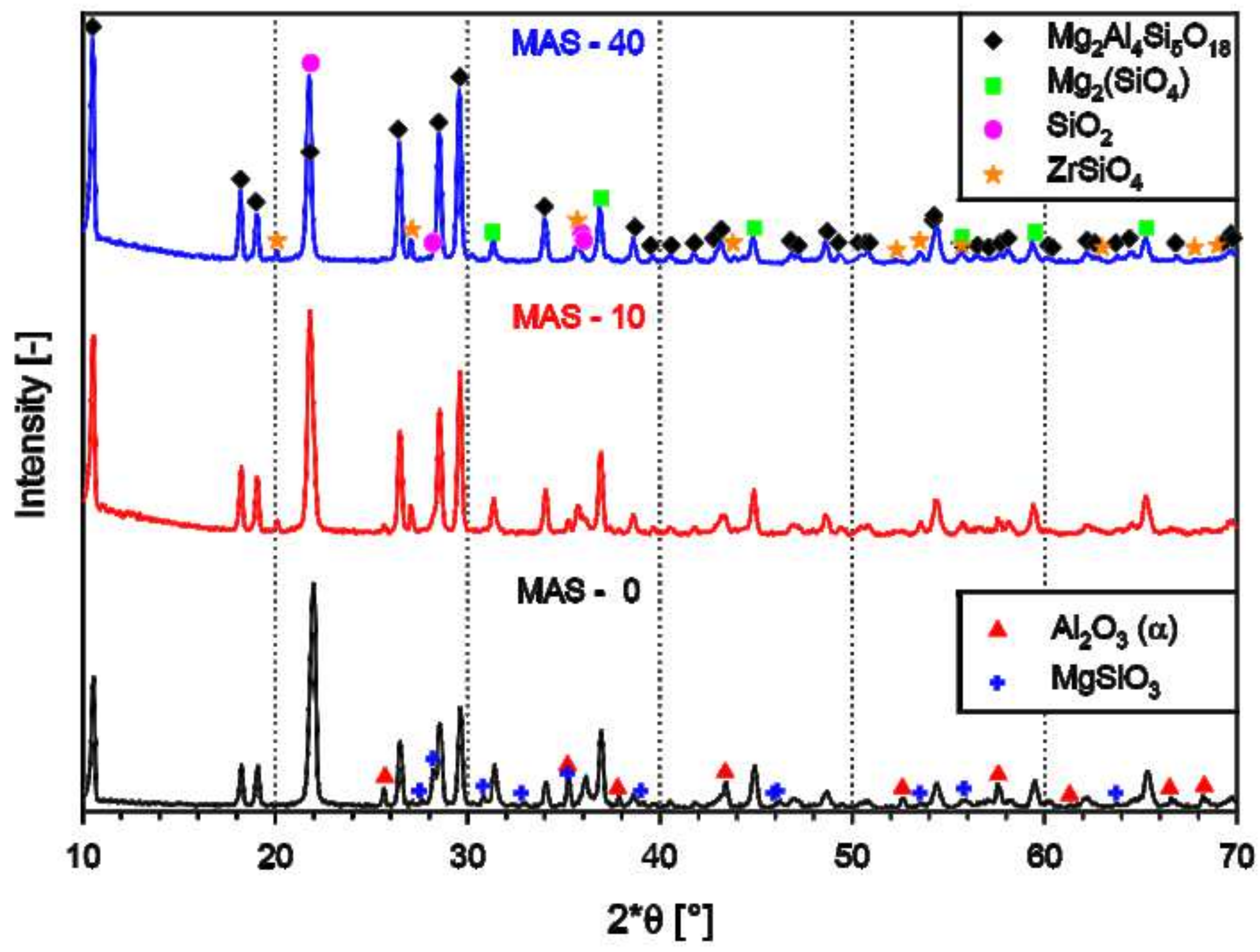




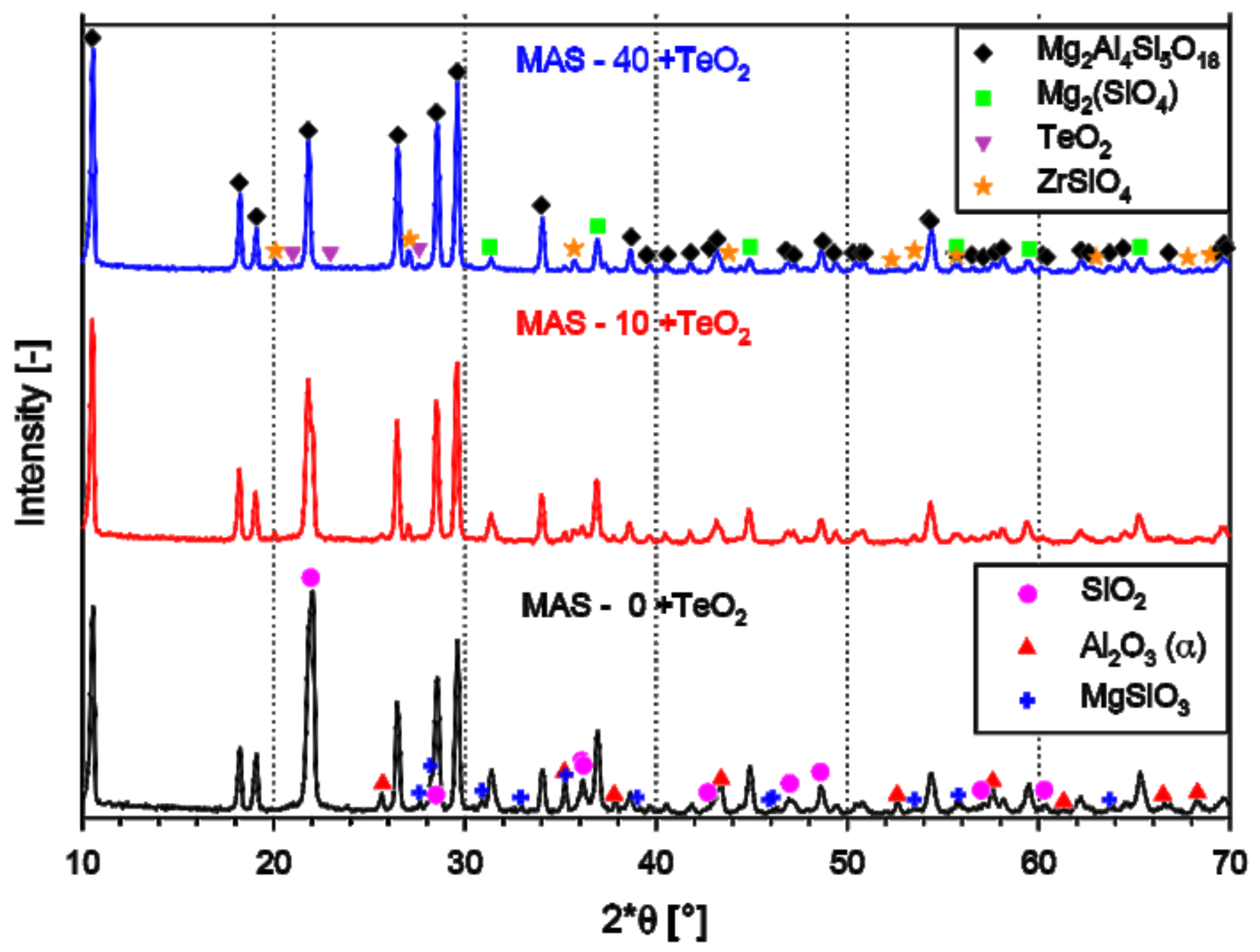




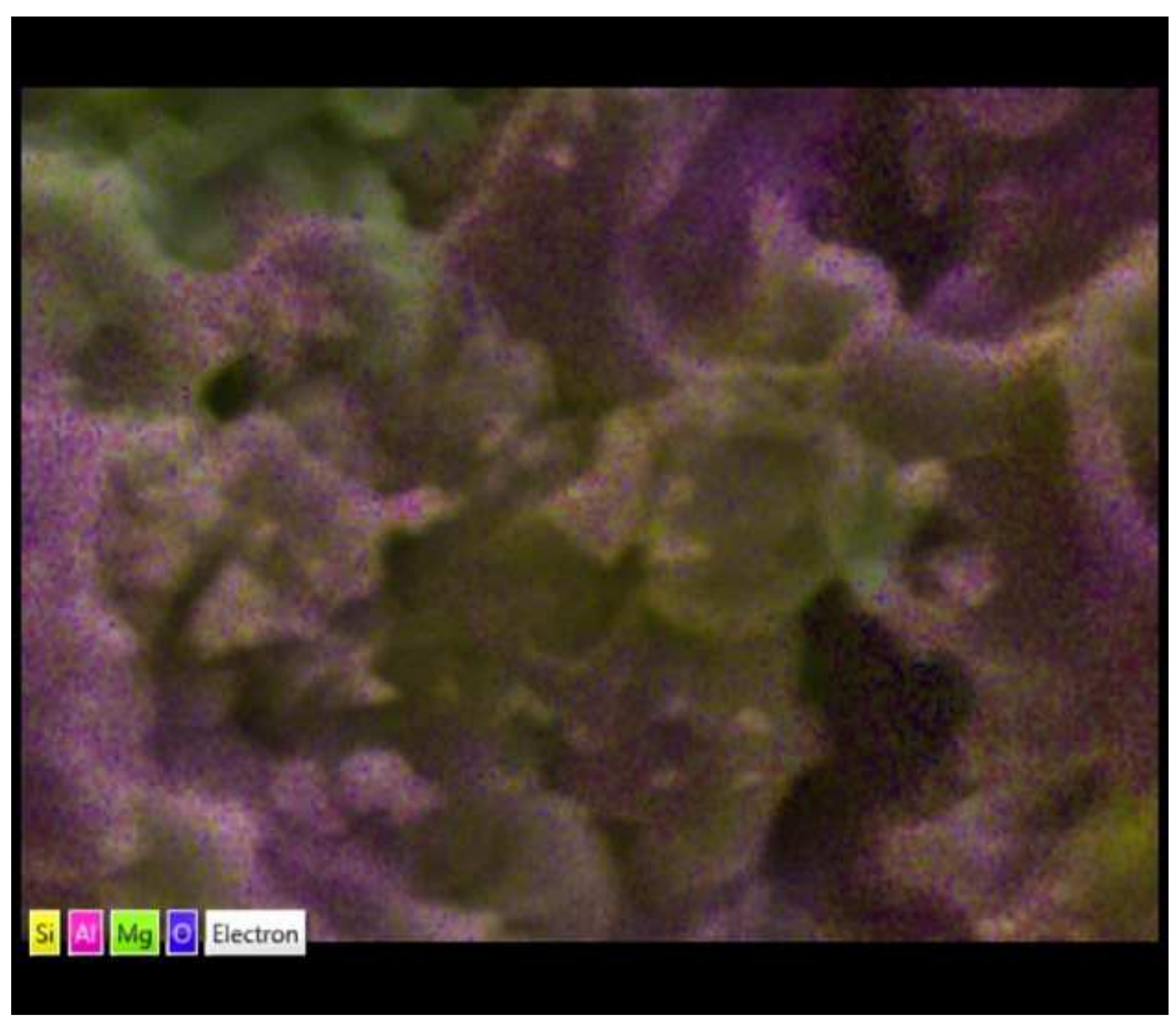




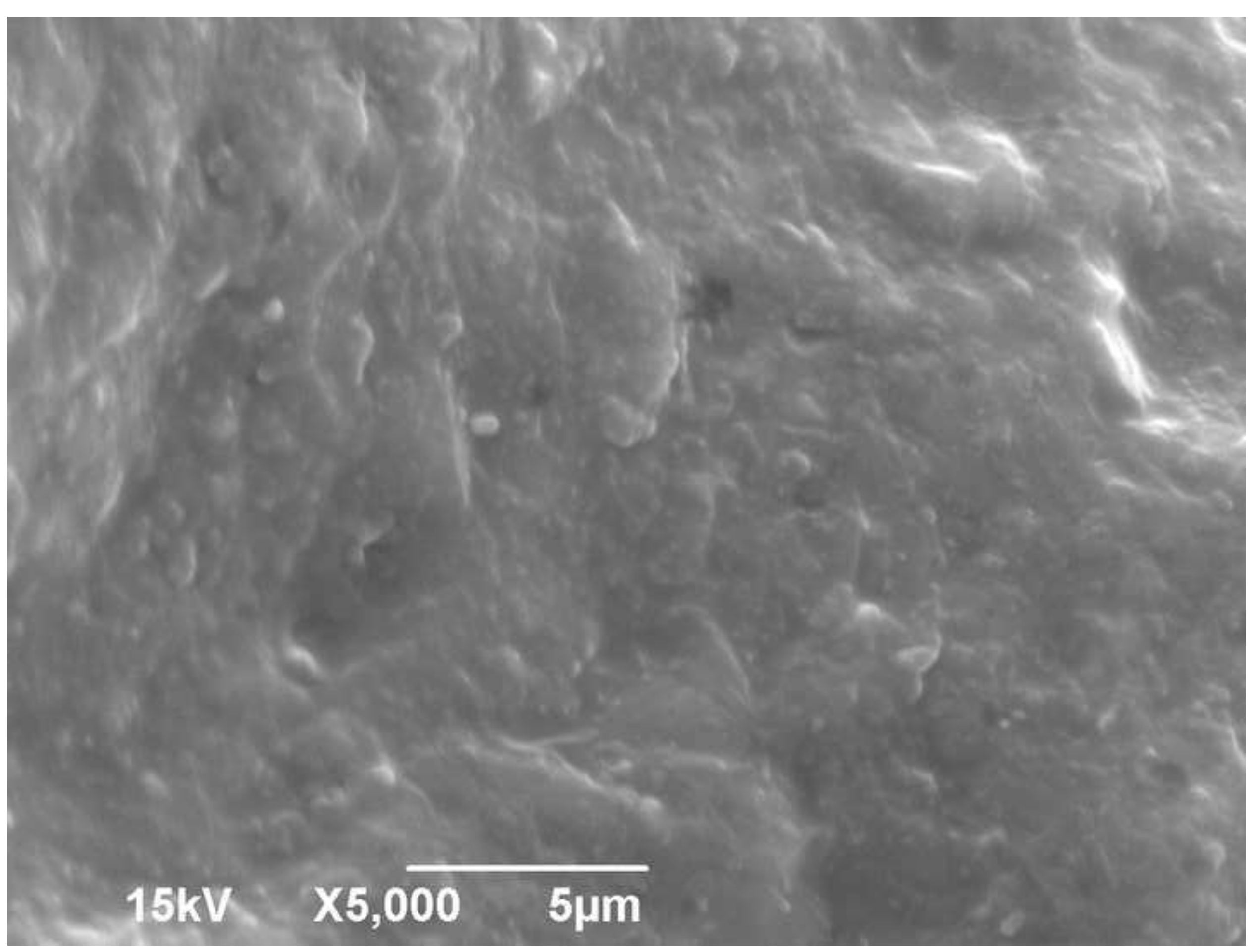




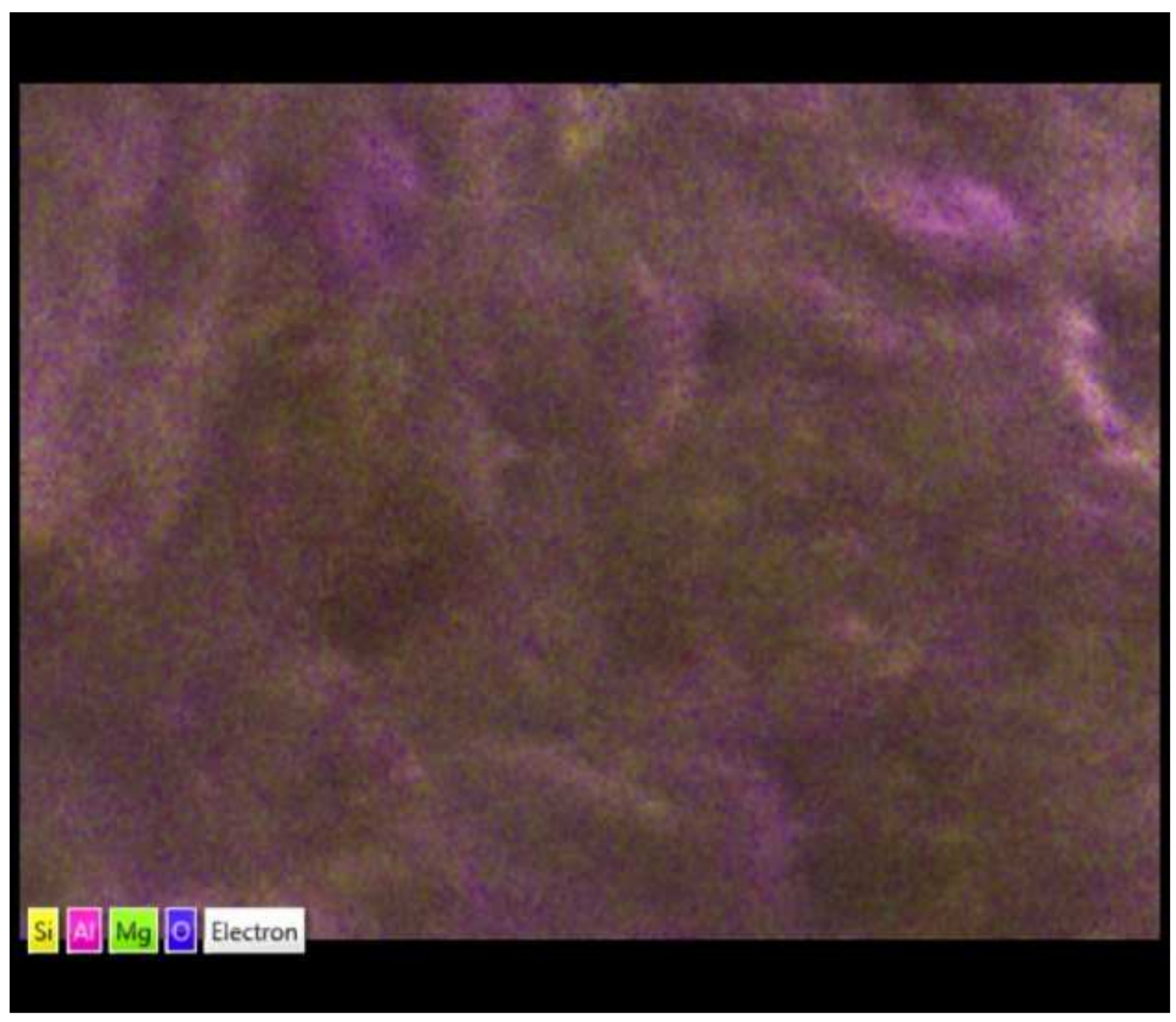


Click here to download Non-colour figure Fig. 5 a.jpg $\underline{\underline{ \pm}}$
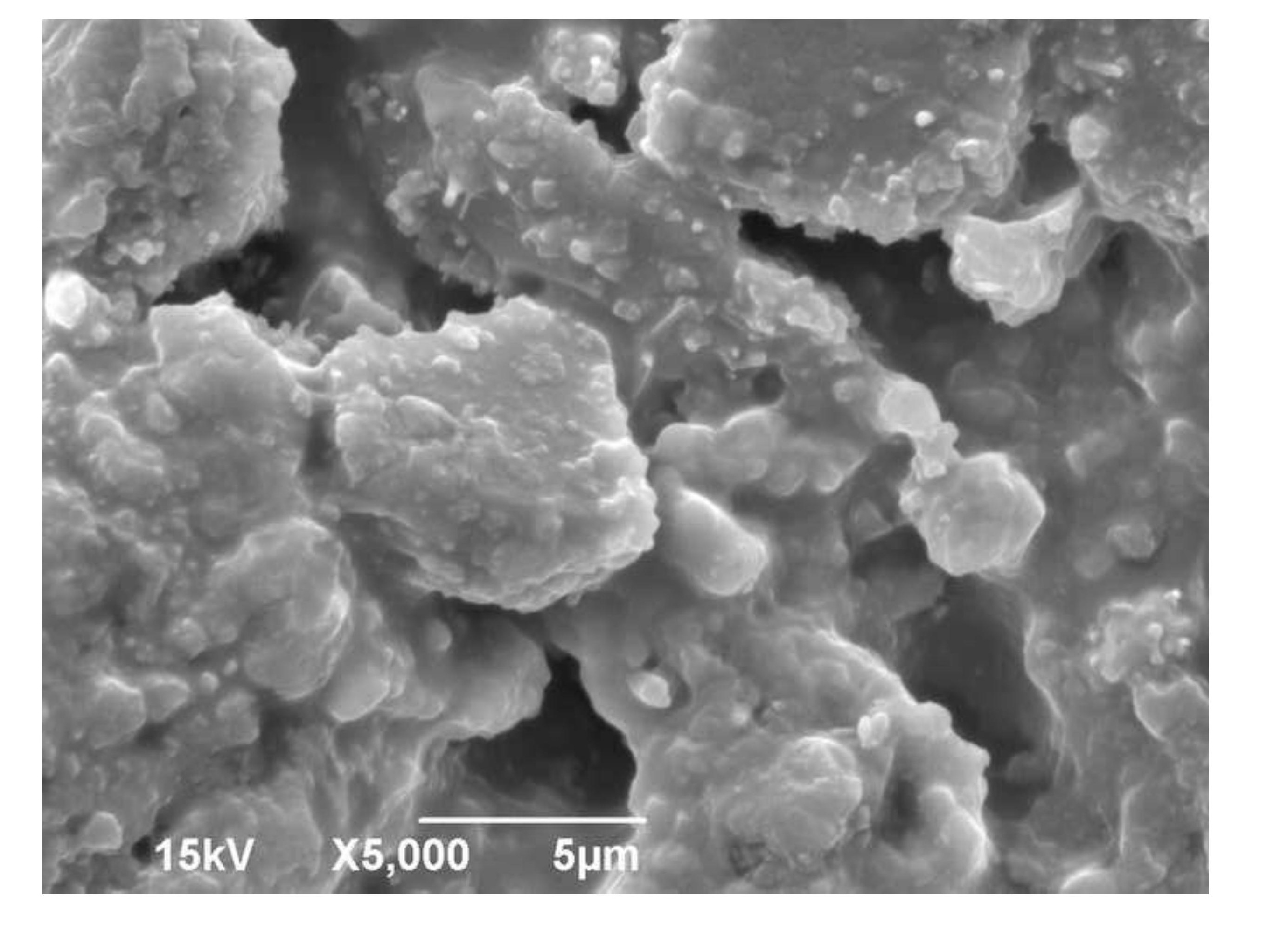

.

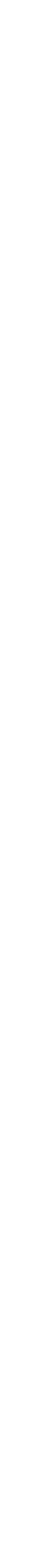

. 


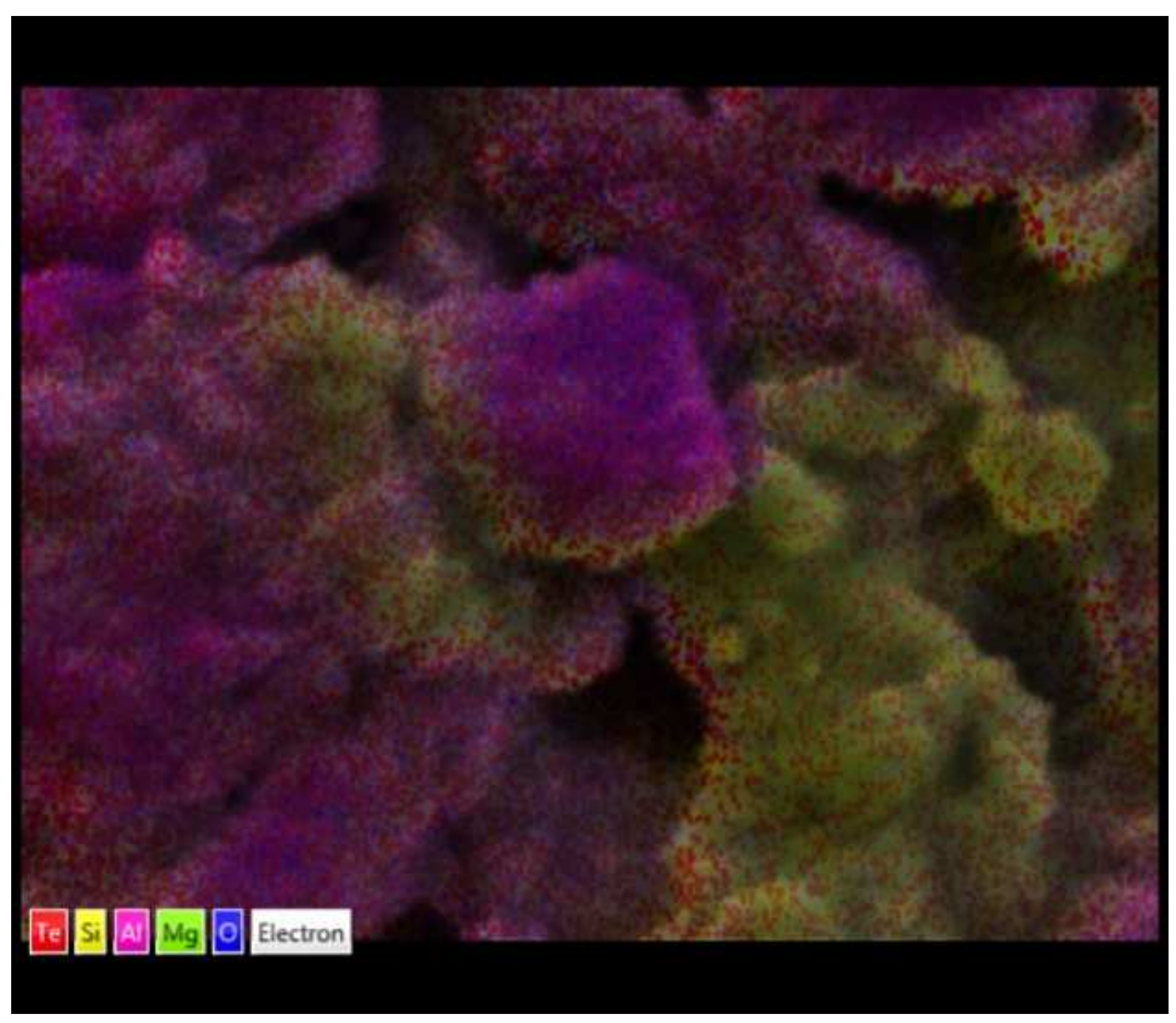




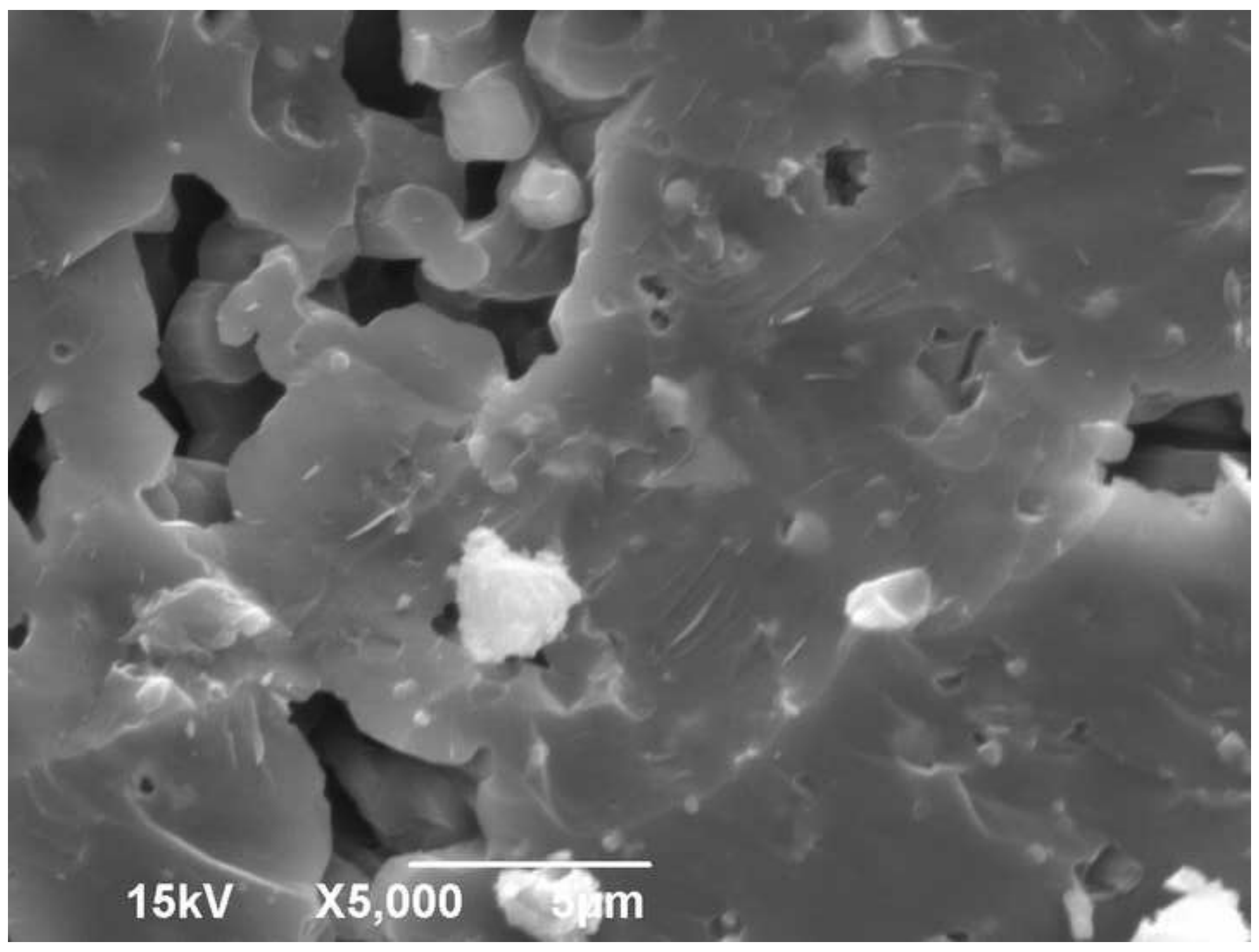




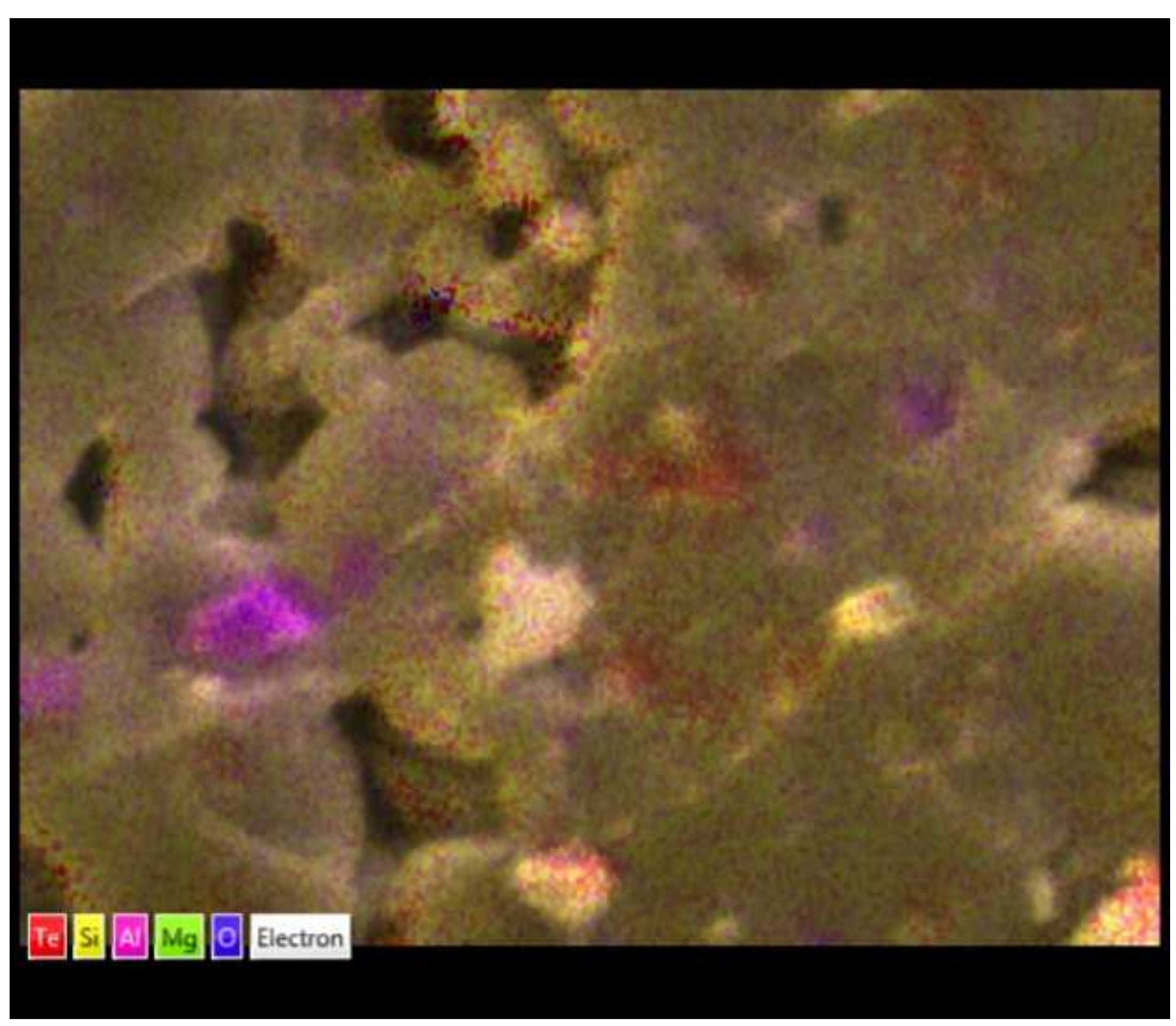




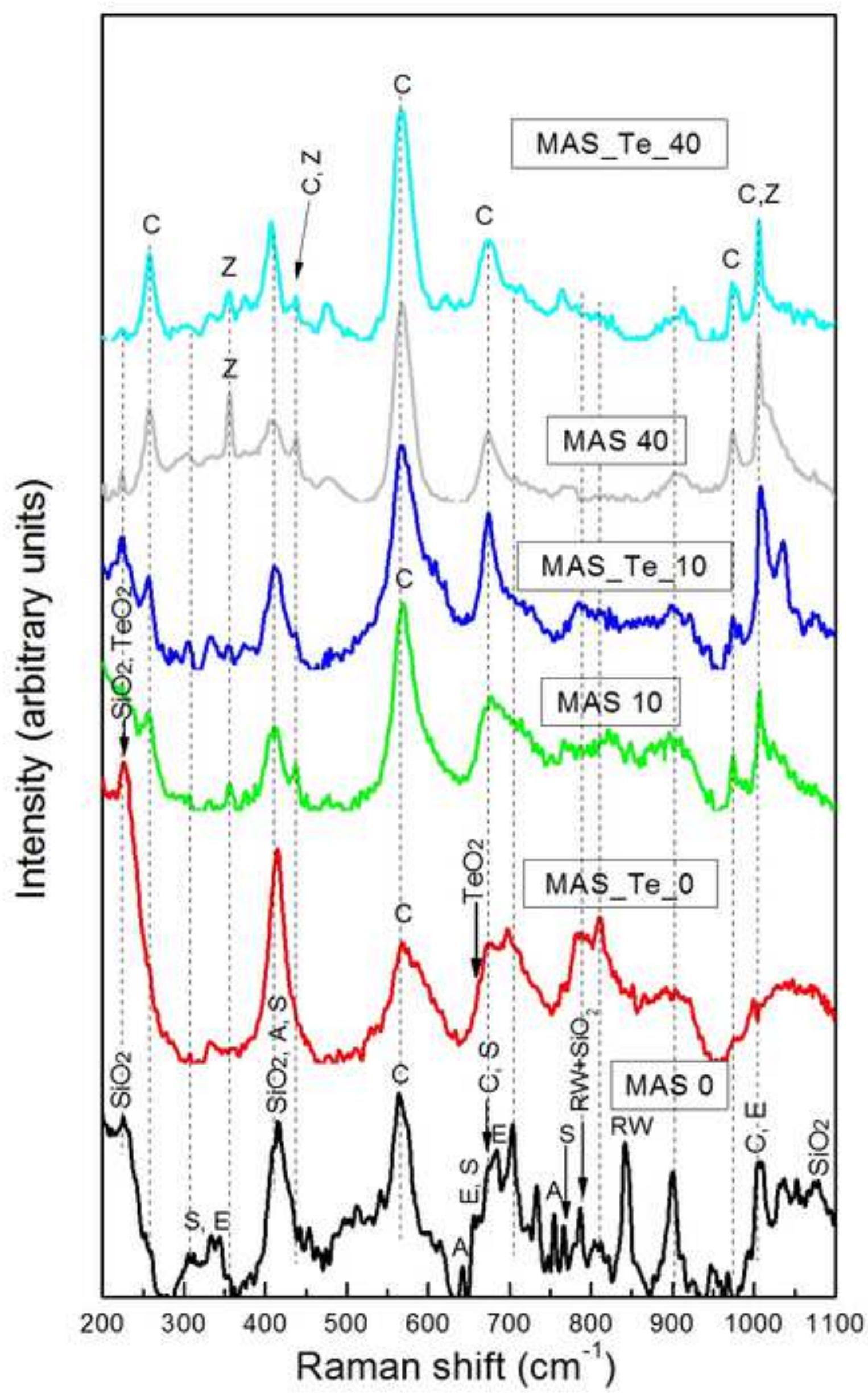




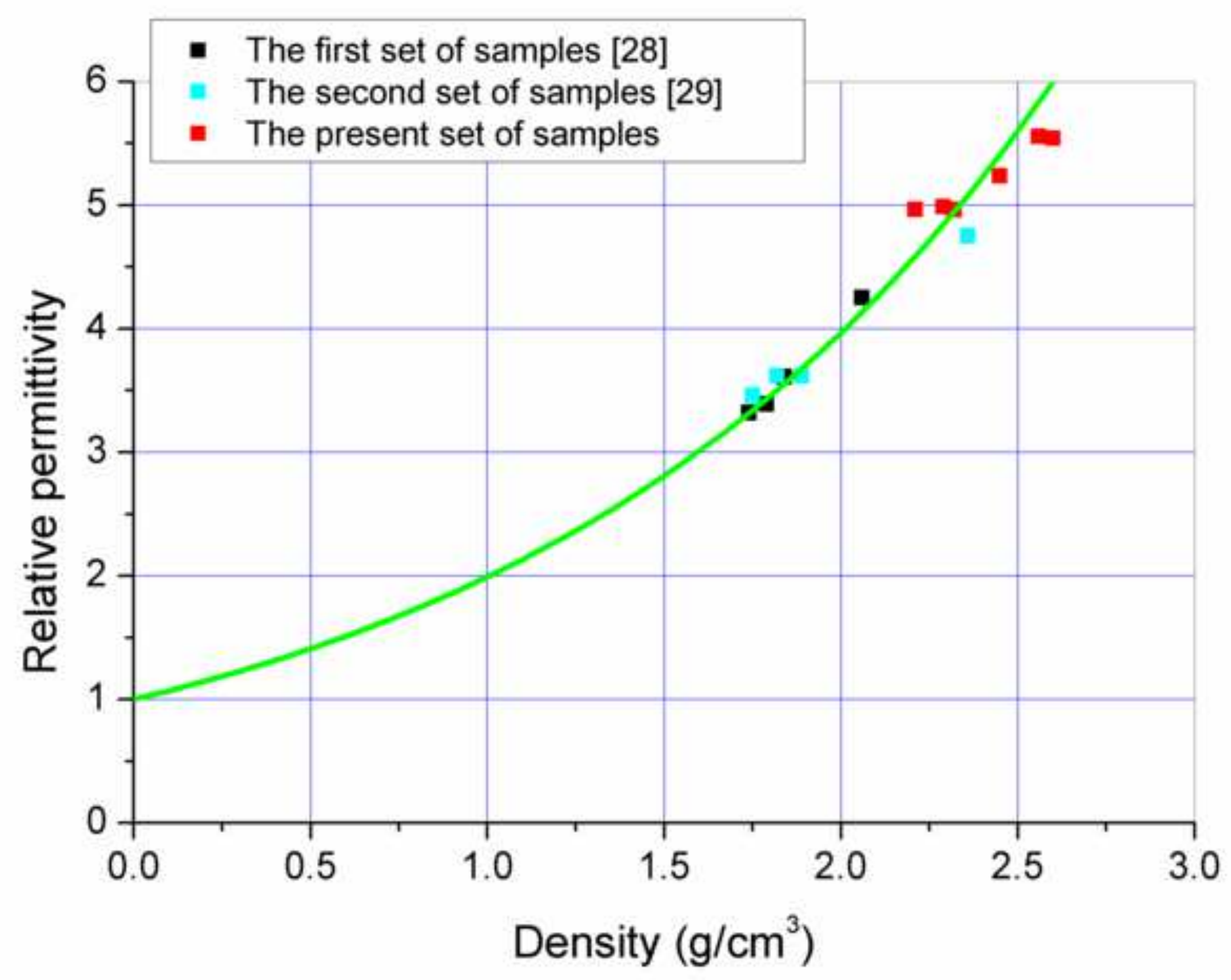

